\title{
AOR
}

Selected Papers of \#AolR2020:

The $21^{\text {st }}$ Annual Conference of the

Association of Internet Researchers

Virtual Event / 27-31 October 2020

\section{CURATING MEMORIES: THE ROLE OF EMOTION IN THE DIGITAL MEMORY WORK OF YOUNG WOMEN ON INSTAGRAM \& FACEBOOK}

Taylor Annabell

King's College London

A core understanding in memory studies is that memory is not formed by an individual in insolation. Instead, it is guided by social frameworks and enacted within a particular social context. This is articulated by van Dijck (2007) as an inseparability of mediated memories from culture. Accordingly, when exploring the way memory is part of the experience of social media platforms, the specific cultural context of individuals engaging in remembering must be considered. Relevant to young women using Instagram and Facebook in London, is the postfeminist, neoliberal environment that places particular expectations and pressures on how young women should feel and act. The purpose of this paper is to specifically explore the role that emotion plays in shaping the performance of digital memory work of young women on Instagram and Facebook.

I follow the approach of Gill (2007) in understanding postfeminism as a sensibility. By this, she refers to the ways that postfeminism is characterised by distinctive, interconnected themes and features, which shape subjectivity. It involves contradictory entanglements of feminist and anti-feminist themes and is intimately tied to neoliberal ideas. It also operates in and through affective and physic registers (Gill, 2017). The 'right' types of dispositions should be displayed, cultivating expectations around how young women are expected to feel and act (Dobson, 2015; Gill, 2017; Kanai, 2019). For example, Kanai (2019) demonstrates how the self is produced as relatable in Tumblr blogs. It requires negative affects to be carefully shared and struggles and failures to be retold and downplayed. Consequently, performance is guided by the 'right feelings'.

Following this, I approach the practices, digital traces, perspectives and experiences of young women in the context of postfeminism may advance an understanding of the way(s) that remembering takes place on, with and through social media platforms. Digital memory work refers to the active, purposeful creation of and re-engagement with digital traces of the past in the present by a memory actor. I echo the perspective of Smit et al. (2018) that digital memory work can be performed by human and nonhuman actors. Agency is distributed between people, algorithms and platforms. This is reflected

Suggested Citation (APA): Annabell, T. (2020, October). Curating Memories: The Role of Emotion in the Digital Memory Work of Young Women on Instagram \& Facebook. Paper presented at AolR 2020: The $21^{\text {th }}$ Annual Conference of the Association of Internet Researchers. Virtual Event: AolR. Retrieved from http://spir.aoir.org. 
in the way that this paper engages with the role of emotion in digital memory work from the perspectives of people and the platform.

I draw on data gathered from semi-structured interviews with young women aged between 18 and 21 living in London, and ethnographic observations of their Instagram and Facebook profiles. The interview involved a scroll-back dimension (Robards \& Lincoln, 2017), in which the participant acted as co-analysts by narrating their digital traces while 'scrolling back' through their profiles. This is complemented with a socioeconomic platform analysis (van Dijck, 2013) and a technical walkthrough (Light et al. 2016) carried out to examine how Instagram and Facebook encourage particular emotions to be expressed and the entanglement of memory and emotion in their memory product. This seeks to advance work on the emotional architecture of Facebook (Wahl-Jorgensen, 2018) and the argument presented by Lambert et al. (2018) that the algorithmic curation of Facebook's Year in Review is underpinned with a celebratory tone.

I explore the overlap between this encouragement by platforms and the expectations of the postfeminist environment for happy moments to be shared with the way that different emotions influence what is shared according to the young women I interviewed. Ahmed (2010) conceptualises happiness as a form of world-making, which provides the horizon. It functions as a form of orientation, which directs people toward certain objects with the expectation that these will provide them with ingredients for a good life. Following this framework, I consider the range of moments and themes pursued by participants. The most dominate is friendships and relationships, celebrations and events, holidays and landscapes and finding the joy in everyday moments. Reading these areas as ingredients for a good life offers insight into how this group of young women conceive of happiness, which can be situated in wider happiness scripts.

On one level, the dominance of happy, positive emotions represents continuity with predigital photography mnemonic practices. Emotion influenced what events were photographed and which photos were kept in photo albums, underpinned by cultural expectations of what the family wished to remember in the future. On another level, the public, connective sharing of photos as well as agency of the platform itself add complexity to mnemonic practices. The On This Day algorithms attempt to determine the emotion of posts in order to resurface 'happy' posts for users as their memories. The encouragement by the platform to share about happy moments and for digital traces to act as vehicles for happy remembering aligns with cultural expectations of what emotions should be expressed and how life should be represented on platforms. Interestingly, this curation and selectivity of representation, known as the 'highlight reel', is also reflected on critically, invoking discourses of authenticity and the perfect.

Teasing out tensions in the expression of negative emotions reveals the way that feeling rules are developed and negotiated on Instagram and Facebook. For some young women, such sharing falls firmly outside of their boundaries of what belongs in these spaces, interpreting it as attention-seeking or self-indulgent. Yet, concern around being authentic and 'real' also emerges particularly in the perspectives and practices of two young women who seek to push back against the expectations to be happy and 
positive. I situate their stories and posts against the visible, public archive of female pain, sadness and feelings of the 'Sad girls of Instagram'. This form of emotional sharing can be seen as a refusal of the affective norms but also, at times, suggests a reinforcement of postfeminist values in that difficulties and weakness are disclosed as part of presenting the self as confident and relatable.

\section{References}

Ahmed, S. (2010) The promise of happiness. Durham, NC: Duke University Press. van Dijck, J. (2007) Mediated memories in the digital age. Stanford, CA: Stanford University Press. van Dijck, J. (2013) The Culture of Connectivity. Oxford, United Kingdom: Oxford University Press.

Dobson, A. (2015) Postfeminist Digital Cultures: Femininity, Social Media, and SelfRepresentation. New York, NY: Palgrave Macmillan.

Gill, R. (2007) Gender and the media. Cambridge, United Kingdom: Polity Press.

Gill, R. (2017) The affective, cultural and psychic life of postfeminism: A postfeminist sensibility 10 years on. European Journal of Cultural Studies. 20 (6), 606-626.

Kanai, A. (2019) Gender and Relatability in Digital Culture: Managing Affect, Intimacy and Value. Cham, Switzerland: Springer International.

Lambert, A. et al. (2018) Algorithmic memorial videos. Memory Studies. 11 (2), 156171.

Light, B. et al. (2016) The walkthrough method: An approach to the study of apps. New Media \& Society. 20 (3), 881-900.

Robards, B. \& Lincoln, S. (2017) Uncovering longitudinal life narratives: scrolling back on Facebook. Qualitative Research. 17 (6), 715-730.

Smit, R. et al. (2018) Activating the past in the Ferguson protests: Memory work, digital activism and the politics of platforms. New Media \& Society. 20 (9), 3119-3139. Wahl-Jorgensen, K. (2018) 'The Emotional Architecture of Social Media', in Zizi Papacharissi (ed.) A networked self and platforms, stories, connections. New York: Routledge. pp. 77-93. 